\title{
IKVAV-linked cell membrane-spanning peptide treatment induces neuronal reactivation following spinal cord injury
}

Spinal cord regeneration following treatment with a novel membrane-spanning peptide (MSP) expressing the isoleucine-lysine-valine-alanine-valine (IKVAV) epitope was assessed in Balb-c mice. After hemilaminectomy and compression injury, mice were treated with IKVAV, IKVAV-MSP, peptide or vehicle control. Functional improvement was assessed using modified Basso, Beattie, and Bresnahan Scale (mBBB) and spinal cord segments were studied histologically 28 days after injury. IKVAV-MSP group scores increased significantly compared with control groups after 4 weeks of observation $(p<0.05)$. The number of protoplasmic astrocytes, neurons and muscle bundle size in the IKVAV-MSP mice were significantly increased $(p<0.001 ; p<0.05$ and $p<0.007$; respectively). This study demonstrates that it is possible to promote functional recovery after $\mathrm{SCl}$ using bioactive IKVAV presenting cell membrane-spanning peptides.

Lay abstract: A new potential treatment for spinal cord injury was tested in mice. Mice were treated with our membrane-spanning peptide with the IKVAV motif (IKVAV-MSP) or various control treatments. Functional improvement was assessed daily and spinal cord segments were evaluated after 4 weeks. IKVAV-MSP treatment significantly restored function compared with control groups, numbers of health nerve cells within the spinal cord were increased and muscles appeared healthier. This study demonstrates that it is possible to promote functional recovery after $\mathrm{SCl}$ using bioactive IKVAV presenting cell membrane-spanning peptides.

Keywords: spinal cord injury $\bullet$ regeneration $\bullet I K V A V \bullet$ regeneration $\bullet$ membrane-spanning peptide

Spinal cord injury (SCI) is a debilitating condition that stimulates complex cellular and molecular interactions in the spinal cord. These interactions include contributions from inflammatory cell activation, reactive astrocytes and the production of both growth promoting and inhibitory extracellular molecules [1]. The cascade of events that occur after SCI at the site of injury often results in incomplete repair of damaged tissue with altered cellular morphology and loss of function. Biological analysis of SCI in mouse models has pointed to both necrotic and apoptotic mechanisms of cell death after injury [2]. Electron micrographs of neurons in gray matter following SCI have shown frag- mented nuclei and condensed bodies along with shrunken cell bodies. Neuronal and glial apoptosis following SCI can contribute to neurological dysfunction, paresis and paralysis [3]. Spinal cord injury also results in glial reaction which recruits microglia, oligodendrocyte precursors, meningeal cells, astrocytes and stem cells.

Activated astrocytes migrate and eventually form a glial scar at the site of the injury which inhibits axon regeneration and recovery of normal function. The glial scar that forms following spinal injury is an evolving structure, with different cells arriving and participating at different stages, to create a final structure that is predominantly astrocytic. This astro-
Soheila Kazemi', Wendy Baltzer ${ }^{1}$, Karl Schilke ${ }^{2}$, Hadi Mansouri ${ }^{3}$ \& John Enrique Mata*,4

'Department of Clinical Sciences, College of Veterinary Medicine, Oregon State University, Corvallis, OR, USA

${ }^{2} S$ chool of Chemical, Biological \& Environmental Engineering, Oregon State University, Corvallis, OR, USA ${ }^{3}$ Department of Biomedical Sciences, College of Veterinary Medicine, Oregon State University, Corvallis, OR, USA ${ }^{4}$ Department of Basic Medical Science, Western University of Health Sciences, Pomona, CA, USA

*Author for correspondence:

Tel.: +1 5412590231

Fax: +1 5412590201

jmata@westernu.edu 
cyte response to injury is referred to as reactive gliosis (more glia) but in fact, in most instances of SCI, the actual amount of glial cell division is relatively small and confined to the immediate penumbra surrounding the lesion core [4-8]. Astrocytes form the majority of the scar and may be responsible for inhibition of neuron regeneration across the site of injury.

We hypothesize that intervention leading to successful regeneration of neuronal tissue within the injured spinal cord will reduce the astrocyte response that contributes to scar formation. Further, more complete regeneration guided by sustained cellular signals will likely result in morphologically normal cellular architecture that will be evident by TEM. To test this hypothesis, we chose a transmembrane-spanning peptide (MSP) that acts as a molecular anchor and presents the IKVAV motif when applied to injured tissue. IKVAV is an active sequence of laminin-1 which is located in the C-terminal end of the long arm of the $\alpha 1$ chain which promotes cell adhesion, neurite outgrowth, angiogenesis, collagenase IV production and tumor growth [9-13]. In a recent study [14], treatment with IKVAV PA (peptide amphiphile) following SCI resulted in reduced astrogliosis and subsequent glial scar as well as reduced cell death. IKVAV also increased the number of oligodendroglia, promoted regeneration of descending motor fibers and ascending sensory fibers and resulted in significant behavioral improvement experimentally in mice.

The specific purposes of this study were to evaluate the response to the IKVAV-MSP within the site of compression injury to elucidate the changes in cellular architecture compared with normal and untreated tissue. We analyzed nerve cells, astrocytes and glial scar formation in the injured spinal cord. In addition, we determined the effect of IKVA-peptide on the rate of muscle atrophy following SCI.

\section{Materials \& methods}

Animal care \& mouse spinal cord injury

All animal procedures were undertaken in accordance with the Public Health Service Policy on Human Care and Use of Laboratory Animals. All procedures were approved by the Institutional Animal Care and Use Committee (IACUC) at Oregon State University. Forty-three healthy skeletally mature Female Balb-c mice (10 weeks of age) were divided into five groups of 7-9 animals each with a nonsurgical group of six normal (untreated group) mice and surgical treatment groups including: vehicle (Mannitol $0.5 \mathrm{mg} / \mathrm{ml}$ ), control (IKVAV $0.5 \mathrm{mg} / \mathrm{ml}$ ), control (Peptide, AELllelellelelll, $0.5 \mathrm{mg} / \mathrm{ml}$ ) and treatment (IKVAV-MSP, AELLLELELLELELLLAIKVAV, $0.5 \mathrm{mg} / \mathrm{ml}$ ). All peptides were synthesized with 95\% purity. We anticipated needing six mice per treatment group based on analysis of preliminary data; however, this number was increased to account for animal loss unrelated to treatment that included three animals in the treatment group removed for excessive chewing of limbs as they regained function, three in the control group and three in the vehicle group that died during the first week, and two in the vehicle group that showed no sign of injury. Animals were anesthetized with isoflurane inhalant (4-5\% induction, $1-2 \%$ maintenance). After laminectomy, at the level of T12 vertebral segment, the spinal cord was compressed dorsoventrally by the extradural application of a $24 \mathrm{~g}$ modified aneurysm clip for $1 \mathrm{~min}$ [15]. Following spinal cord injury, the incision was closed using metal staples (Autosuture, Norwalk, CT). Postoperatively, animals were kept in cages placed on a circulating water pad $\left(80^{\circ} \mathrm{F}\right)$ to prevent hypothermia and $1.0 \mathrm{ml}$ injection of saline was administered once daily subcutaneously (s.c.) to prevent dehydration. Blocked bladders were manually emptied (by finger pressing the bladder over the pelvic region) two to three times daily throughout the study. We used phenoxybenzamine $(5-10 \mathrm{mg} /$ $\mathrm{kg}$, orally) to address urine retention and bladder distention. Phenoxybenzamine is used to reduce internal urethral sphincter tone. It may also be used for urethral spasm secondary to bacterial urethritis [16]. Buprenorphine was given $(0.05 \mathrm{mg} / \mathrm{kg}$, s.c., twice daily) for analgesia in the event that the animal showed signs of discomfort (such as chewing, anorexia and other signs of pain). Enrofloxacin was administered once daily in the event of hematuria or self-mutilation $(5 \mathrm{mg} / \mathrm{kg})$ orally for $5-7$ days. Two mice that exhibited any hind limb movement less than $24 \mathrm{~h}$ following the injury were excluded from the study.

\section{Peptide injection}

IKVAV-MSP $(0.5 \mathrm{mg} / \mathrm{ml}, 1 \%$ Phosphate Buffered Saline, $2.5 \%$ mannitol solution) or other treatments including control peptides at equal molar concentrations, were administered $24 \mathrm{~h}$ after injury using tuberculin syringes with a fine (25 gauge) needle. Under isoflurane anesthesia, the skin sutures were removed and the site of injury (subcutaneous portion) was exposed. A micropipette was inserted just under the granuloma formed at the site of injury dorsally on the spinal cord, and $10 \mu \mathrm{l}$ of the IKVAV-MSP solution (approximately $5 \mu \mathrm{g}$ total) or other treatments were applied to the injury site. The needle was carefully withdrawn and the wound was closed. For all experiments, the investigators were kept blind to the identity of the treatment groups. 
Modified Basso, Beattie \& Bresnahan Scale openfield locomotion score

To assess behavioral recovery from SCI, the modified Basso, Beattie and Bresnahan Scale (mBBB) openfield locomotion score was observed using the $\mathrm{mBBB}$ Locomotor Rating Scale which we found to be more discriminating for than the method described by Basso et al. [17-19]. For examination, the mice were placed individually in an open field on a non-slippery surface. The 22-point (0-21) mBBB scale was used to assess hind limb locomotor recovery including joint movements, stepping ability, coordination and trunk stability. A score of 21 indicates unimpaired locomotion as observed in uninjured mice whereas a score of 0 indicates complete absence of voluntary movement. The tests were performed by two examiners who were blinded to the animal's treatments. Mice were assessed prior to injury and $\mathrm{mBBB}$ tests were performed every day after injury till the end of the study (28 days).

\section{Animal tissue acquisition \& preparation}

On day 28, animals were euthanized with an overdose intraperitoneal pentobarbital (beuthanasia-D, Schering-Plough Animal Health Corp., NJ, USA) $100 \mathrm{mg} / \mathrm{kg}$ ( $0.2 \mathrm{ml} / \mathrm{mouse})$ and the spinal cords were removed after complete laminectomy at the site of the injury and immediately placed in $2 \%$ buffered formalin. The spinal cords were kept in the refrigerator overnight and then transferred to the electron microscopic laboratory for routine tissue processing. Semi-thin sections $(0.5 \mu \mathrm{m})$ were cut using a Sorvall MT2-b (Norwalk, CT, USA) microtome for light microscopic observations and then ultrathin sections $(60 \mathrm{~nm})$ were cut with a diamond knife and put on 100 mesh copper grids for transmission electron microscopic observation using Philips CM/12 STEM (Eindhoven, Netherlands).

\section{Muscle preparation}

Hamstring and quadriceps muscles were dissected from all groups and fixed in 2\% buffered formalin for $24 \mathrm{~h}$. Segments were embedded in paraffin and processed routinely for light microscopic evaluation of $5 \mu \mathrm{m}$ sections stained with hematoxylin and eosin (H\&E).

\section{Neuron \& muscle bundle size quantification}

The computer software ImageJ (Wayne Rasband, NIH, USA) was used to measure the neuron and muscle size. We used micrometer $(\mu \mathrm{m})$ as a unit for measuring the surface of each neuron and each muscle bundle.

\section{Protoplasmic astrocyte quantification}

Astrocytes were counted in three fields of each semithin section for each mouse at 400 magnification using calibrated ocular lens with Lattice lines.

\section{Statistical analysis}

Two-way ANOVA and general linear model were used to analyze the data. Differences in mBBB scores, body weight between group means and protoplasmic astrocytes numbers were analyzed using two-way ANOVA (mBBB analysis included a repeated measures test). Neuron and muscle size means were identified using linear model test and a significance level of $\mathrm{p}<0.05$. Statistical analysis was carried out using the open source statistical programming arrangement ' $R$ ' [20]. Statistical significance is noted with asterisk as ${ }^{*}=\mathrm{p}<0.05$; $^{* *}=\mathrm{p}<0.01 ;^{* * *}=\mathrm{p}<0.001$.

\section{Results \& discussion}

To assess the functional recovery of the spinal cord and measure the basis of the functional recovery following injury, several outcome parameters were used including $\mathrm{mBBB}$ score, histological and electron microscopy. At 4 weeks after SCI, IKVAV-MSP mice displayed a significant improvement in neurological status $(\mathrm{p}<0.05)$, whereas none of the other treatment groups were significantly altered from their immediate postoperative status (Figure 1).

\section{Effect of the IKVAV-MSP on protoplasmic astrocytes}

As seen in Figure 1, IKVAV-MSP significantly improved neurological recovery following acute SCI, with improvements in motor function evident as early as 4 weeks following treatment. At 4 weeks following SCI, ocular counting of light-microscopic sections of injured spinal cords identified increased numbers of protoplasmic astrocytes in the IKVAV-MSP treatment group compared with IKVAV, Normal and Mannitol groups ( $<$ 0.001) (Figures 1 \& 2). However, IKVAV-MSP was not significantly different from the peptide-treated group $(\mathrm{p}>0.05)$.

\section{Effect of the IKVAV-MSP on neuron size \& neuron cell death}

Injury-induced apoptosis can be detected from hours up to days following injury and may contribute to neurological dysfunction [21]. We used ImageJ software to measure the size of the neurons in each of the treatment groups to determine whether the injection of the IKVAV-MSP could support cellular regeneration of the motor neurons. The images of all sections were taken using a light microscope equipped with a digital camera (DFC280 Model, Leica Microsystems Ltd) [22], with 400 magnification. There was a significant increase in the size of the neurons of the gray matter in the IKVAVMSP mice compared with the other four groups ( $\mathrm{p}<$ 0.05 , Figures $1,2 \& 3$ ). Neuron reactivation as evinced by increase in metabolic activity was seen in the gray mat- 


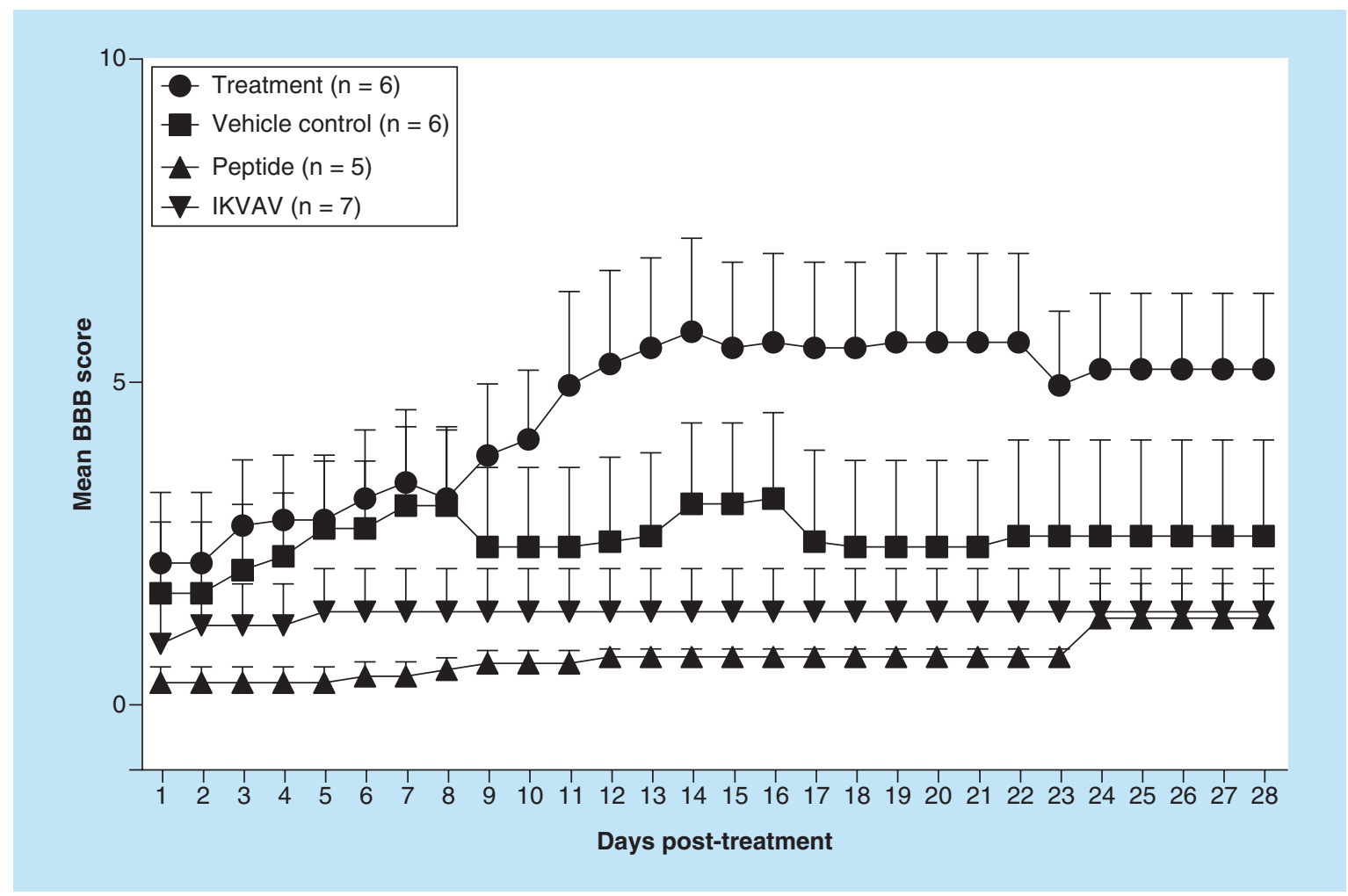

Figure 1. Effects of IKVAV-membrane-spanning peptide treatment on neurological status with daily assessment for $\mathbf{2 8}$ days following spinal cord clip compression injury. Two-way ANOVA followed by Tukey's multiple comparison test revealed a significant improvement in locomotor control compared with peptide alone on days $11-28(p \leq 0.05)$ and IKVAV alone on days $11-28(p \leq 0.05)$.

ter of the spinal cord at the site of injury. Neuron degeneration and death were detected using light microscope (LM) and transmission electron microscope (TEM) micrographs. The characteristics of neuronal death that were examined, included apoptosis and necrosis. These included shrunken cell bodies with intact cell membranes, chromatolysis evidence such as dispersed Nissl's substances, and finally a loss of these cellular organelles throughout the cytoplasm along with loosely dispersed nuclear chromatin. Few expanded empty spaces were also noticed between the neuron cell bodies in IKVAV, Peptide and Mannitol mice. Using LM and TEM images we observed 1.4-2.4-folded larger neurons in the IKVAV-MSP group.

\section{Effect of the IKVAV-MSP on muscle size}

Each section was photographed using digital camera connected to the light microscope, with 400 magnification. To measure the muscle bundles we used ImageJ software to assess the degree to which SCI with and without treatment can affect muscle morphology. The results of this measurement indicated that the size of muscle bundles in IKVAV-MSP-treated group was significantly increased compare with IKVAV and Peptide groups $(\mathrm{p}<0.05)$ but not with Normal and Mannitol-treated mice $(\mathrm{p}>0.05)$ (Figure 4). Control treated groups showed identified atrophied muscle bundles with considerable amount of muscular fat (Figure 4C-E).

\section{Effect of the IKVAV-MSP on body weight}

The body weight was measured for each mouse daily, using a digital scale. Losses in body weight from prestudy values were similar between IKVAV-MSP (average loss of $4.4 \pm 1.7 \mathrm{gm}$ ) and the other three groups with Vehicle, IKVAV and peptide groups lost an average of $4.9 \pm 1.3,6.0 \pm 1.6$ and $5.3 \pm 2.4$, respectively.

\section{Discussion}

The pathophysiology of acute SCI involves primary and secondary mechanisms of injury [23-26]. These mechanisms involve the initial mechanical damage leading to secondary injury processes that contribute to further tissue loss, functional impairment, and lesion size increase $[27,28]$. Secondary injury involves the apoptotic and necrotic death of neurons and glial cells $[29,30]$. The microscopic evaluation of neuron death within the lesion site in this study is consistent with other studies, which have described similar amounts of apoptosis and necrotic death after SCI [3,21,30-33]. Although SCI leads to neuronal death, we have seen small numbers of surviving neurons with normal intact structure within the lesion site, which is consistent with other studies using 
the clamp model [34]. In the present study, IKVAVMSP-treated mice revealed the largest number and size of neurons compared with all other groups $(\mathrm{p}<0.05)$, thus indicating that the IKVAV-MSP induced a progressive metabolically active phase in these neurons to regain their normal function. However, in the other groups, reduction of neuron size characterized with shrunken cell cytoplasm may have represented necrotic and apoptotic phases of SCI, which is in agreement with other reports at 28 days postinjury [3].

The SCI was induced with the clamp crush method which is a technique relevant and similar to clinical spinal cord injury in humans [18]. In order to mimic clinical delays in definitive treatment while the patient is stabilized following SCI, we also chose to administer treatment approximately $24 \mathrm{~h}$ following surgery. Recovery was incomplete 28 days following treatment, however, IKVAV-MSP treatment promoted significant functional improvement that can be attributed to the observed differences in neuronal cell death and astrocyte function. Although reactive astrocytes may form a glial scar that can, in some cases, prevent axonal regeneration, they also have a crucial role in wound healing and functional recovery following SCI. Emergence and migration of reactive astrocytes have a prominent role in the repair of injured tissue and the restoration of motor function in the subacute phase of healing neuronal tissue before completion of the glial scar [35]. Loss of astrocyte activities during the cellular response to SCI can lead to gross functional deficits and failure of functional recovery and suggest that reactive astrocytes not only protect tissue but also preserve function after SCI [36,37].

In this experiment, IKVAV-MSP treatment improved neurological function and resulted in an increase in the number of astrocytes. Our results support the positive role of astrocytes in promoting neuron regeneration across the site of injury. Interestingly, the Peptide-treated group had a similar increase in the number of astrocytes at the site of injury compared with the IKVAVMSP group. However, neurological function was not improved in this group suggesting that IKVAV must be present on the peptide to achieve successful restoration of movement. The reason for similar numbers of astrocytes between these groups is unknown and further investigation into the mechanism of astrocyte induction with the membrane-spanning peptide is warranted. Compelling evidence indicates that formation of a glial scar inhibits axonal regeneration 4 weeks after SCI [8]. In agreement with this finding, we observed functional behavioral scores reached a plateau from week 3 to week 4 . Reactive astrocytes divide and slowly migrate into CNS injuries, eventually to fill in the vacant space and most of a glial scar is made up of astrocytes. Whether astrocytes inhibit or promote neuronal growth has been investigated [38]. Multiple models have demonstrated the molecular composition of the glial scar and production of inhibitory molecules by astrocytes are contributing factors for regenerative failure of axons following injury [39-43]. Yet other studies suggest there is a promoting effect of astrocytes on axonal regeneration $[8,35,36,44]$. The in vitro evidence for the ability of astrocytes to promote or inhibit axon regeneration is conflicting. In our study, mice treated with IKVAV and a transmembrane-spanning peptide or a transmembrane-spanning peptide alone, had increases in astrocytes at the site of injury. In contrast to the peptide alone-stimulated astrogliosis without neuronal recovery, IKVAV-MSP treatment produced neuronal recovery which occurred along with astrogliosis. Further research is warranted to determine why this difference in functional outcome with a similar increase in astrocytes occurred. However, treatment success with IKVAV-MSP was definitive by our measures.

A major concern for patients following SCI is skeletal muscle atrophy. In rodent models of SCI, skeletal muscle atrophy is associated with smaller muscle bundles and an increase in intramuscular fat (IMF). Moreover, IMF continues to increase over time in incomplete SCI [45]. IKVAV-MSP treatment prevented muscle atrophy as evinced by increased muscle mass,

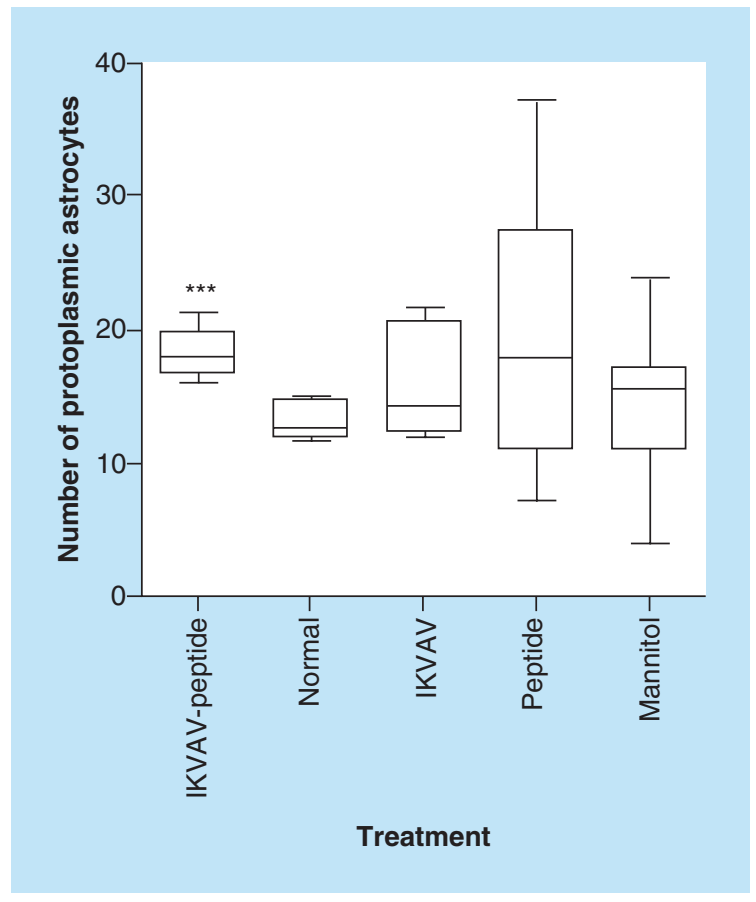

Figure 2. Effects of IKVAV-membrane-spanning peptide treatment on protoplasmic astrocyte number within the area of injury for each group of mice. Three fields were viewed, enumerated and averaged for each mouse. $* * *$ denotes significantly increased numbers of astrocytes compared with all groups except the Peptide group $(p<0.001)$. 


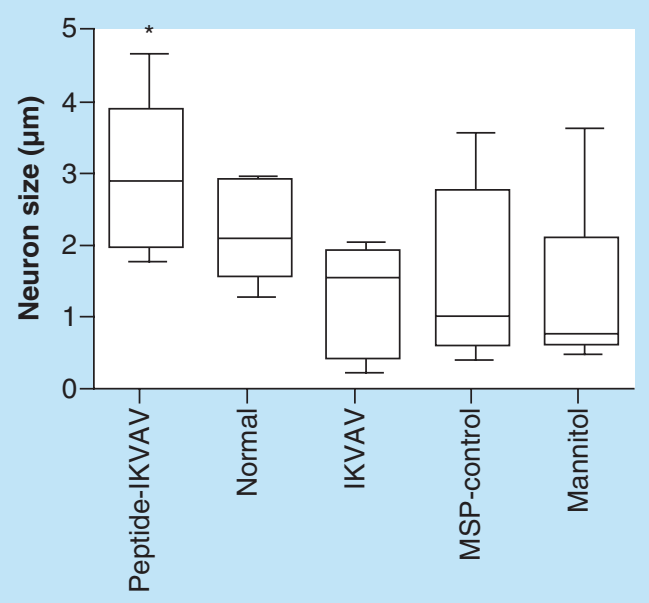

Treatment
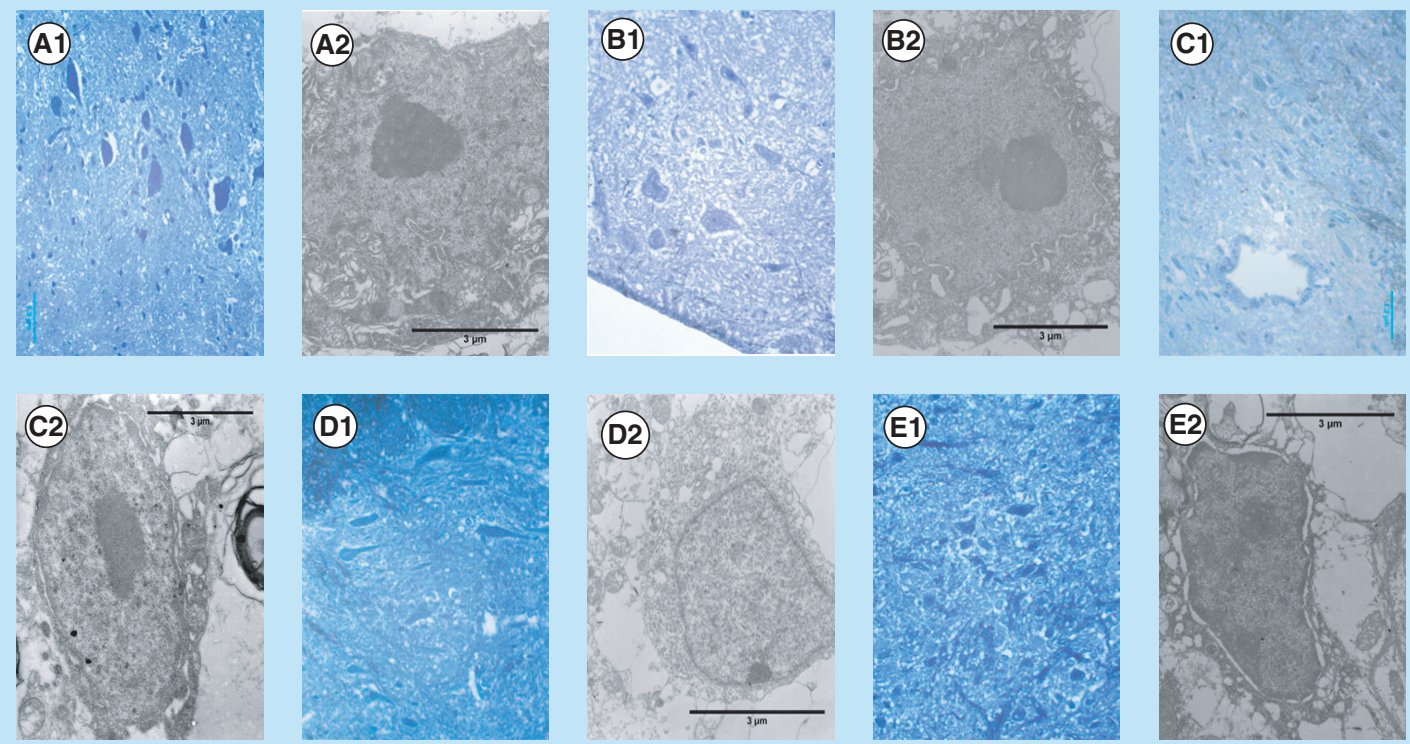

Figure 3. Effects of IKVAV-membrane-spanning peptide treatment on neuron size. Graph shows mean neuron size at 4 weeks after $\mathrm{SCl}$ for all animals determined by measurement of 6 neurons per mouse within the region of interest. * denotes that IKVAV-MSP differed from all others at $p<0.05$. The pictures presented in A-E shows the comparison between representative groups at light under 400X magnification (1) and electron microscope (2) level. In IKVAV-Peptide group (A), the large neurons are obvious and actually larger compared with Normal (B); however, in control groups IKVAV (C), Peptide (D) and Mannitol (E) the neurons are shrunken and in some cases pyknotic.

larger muscle bundle size, and decreased IMF. Further, functional improvement in IKVAV-MSP mice indicates the re-innervation of locomotory muscles.

Our results are significant because none of the mice in our study received physical therapy or exercise of any kind other than being allowed free movement within their cage; yet, mice treated with the IKVAVMSP did not develop the muscle atrophy and increase in IMF seen in the other treatment groups. Increases in muscle mass are possible even years after injury if the appropriate mode and intensity of exercise are utilized even without spinal cord neuron recovery [46,47]. Unilateral neuromuscular electrical stimulation (NMES) can evoke hypertrophy in the knee extensor and adjacent skeletal muscle groups and is associated with a reduction in IMF in human beings with chronic SCI. However, it seems rebuilding muscles after SCI needs more time in order to obtain the increased muscle mass that occurs with physical therapy.

Time is an important factor for recovery following injury. We followed the mice for 28 days post-SCI using a similar model as Tysseling et al. which reported 
IKVAV PA-injected group displayed significant behavioral improvement at 5 weeks and thereafter, compare to the control group [14]. Surprisingly, treatment with our IKVAV-MSP resulted in significant functional recovery observed approximately 1 week after SCI and reached a plateau in improvement of function at week 4. In addition to marked improvement in $\mathrm{mBBB}$ scores at week 1 , several mice displayed self mutilation. A total of 13 mice chewed on their feet or tails with the majority of the mice in the IKVAV-MSP and Mannitol treatment groups (6 mice in total; Mannitol: 4 mice; Peptide: 2 mice; and IKVAV: 1 mouse). Self-mutilation indicated to us the mice may have been regaining feeling in their extremities. In addition to this, some of the mice were not able to urinate possibly because SCI is known to interrupt neuronal circuits which control the bladder function [48]. Interestingly, in the last week of the study most of the IKVAV-MSP treated mice regained their ability to urinate (4/6) suggesting reinnervation with restoration of function [14].
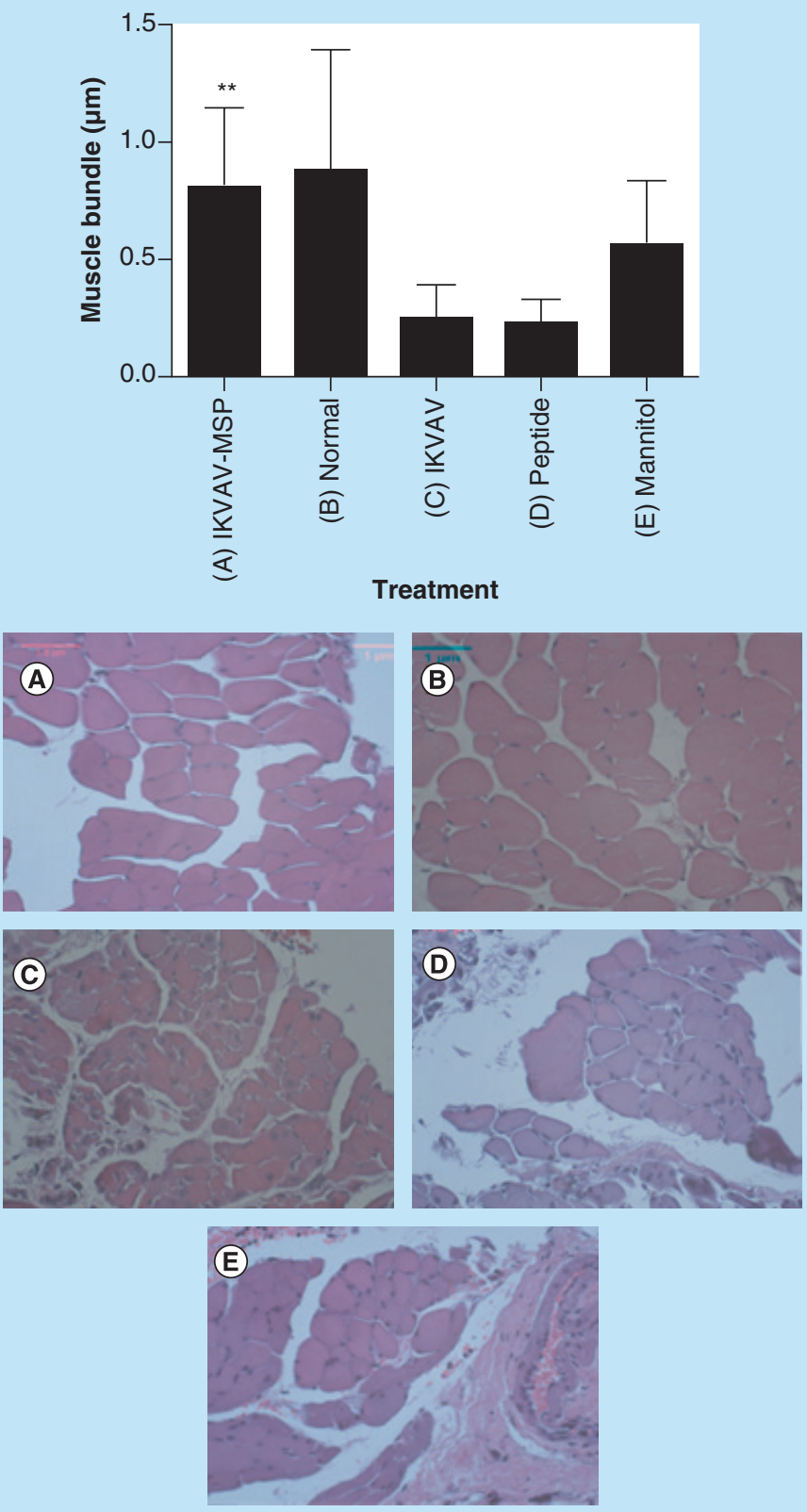

Figure 4. Effects of IKVAV-MSP on muscle bundle size determined from enumeration of 10 fields from both right and left legs for each mouse. ** denotes a significant difference between representative treatment and control groups ( $p<0.01$ ). Comparison of muscle bundles in IKVAV-MSP treated (A), normal untreated (B) and control treated groups (C-E, IKVAV, Peptide and Mannitol treatment, respectively). Histological images are H\&E X400. 
Our observations are similar to kinematic studies of locomotor recovery following SCI in rats with the thoracic clip compression model reporting that during the 6-week postinjury period, a significant amount of spontaneous locomotor recovery occurred in $80 \%$ of the rats with a return of well-defined locomotor hind limb pattern. However, substantial residual abnormalities persisted up to 6 weeks after SCI including postural deficits [49].

\section{Future perspective}

Further research using greater numbers of animals and following the recovery and neuron regeneration over a longer period of time such as 3-6 months is warranted to determine whether the improvements seen in the short term using IKVAV-MSP are maintained later in the regenerative process. Additional studies will also likely include electromyography and anterograde tracing to provide additional evidence of neural regeneration. The results suggest a role for cell-spanning peptides as a platform nanotechnology for the treatment of injury or disease.

The use of molecular anchors to present bioactive molecules in tissue and direct regenerative activities of stem cells in vivo has the potential to accelerate the development of stem cell therapies. Our findings and our previous work suggest that membranespanning peptides could be used to direct signals for regeneration and repair to injured tissues by direct injection into the site or intravenous administration as was previously demonstrated [50]. As the field progresses we anticipate that membrane-spanning peptides could be used to display an array of bioactive molecules capable of directing complex cellular processes.

\section{Author contributions}

All authors contributed to the preparation of the final manuscript, individual contributions are as follows: J Mata con- ceived the idea to use the MSP peptide to deliver biotopes to tissue and is responsible for the original design of the peptide along with K Schilke. S Kazemi assisted in surgery, performed daily assessments with Mansouri, prepared tissues for sectioning and histology, read and enumerated cells in histological samples, assisted in electron microscopic analysis and performed statistical tests with MW Baltzer performed surgeries and oversaw the overall project design and conduct with J Mata. K Schilke designed and oversaw the synthesis of the peptides along with J Mata. H Mansouri performed daily assessments along with Kazemi, prepared samples for the electron microscope, conducted the SEM analysis. Mansouri also provided much of the assessment of the histological data as his area of expertise is the morphometric analysis of neural tissue.

\section{Financial \& competing interests disclosure}

This study was financially supported by Oregon State University Department of Biomedical Sciences Pilot Project Grant. The authors have no other relevant affiliations or financial involvement with any organization or entity with a financial interest in or financial conflict with the subject matter or materials discussed in the manuscript apart from those disclosed.

No writing assistance was utilized in the production of this manuscript.

\section{Ethical conduct of research}

The authors state that they have obtained appropriate institutional review board approval or have followed the principles outlined in the Declaration of Helsinki for all human or animal experimental investigations. In addition, for investigations involving human subjects, informed consent has been obtained from the participants involved.

\section{Open Access}

This work is licensed under the Creative Commons Attribution 4.0 License. To view a copy of this license, visit http://creativecommons.org/licenses/by/4.0/

\section{Executive summary}

- Cell membrane-spanning peptides displaying the isoleucine-lysine-valine-alanine-valine biotope enhance regeneration of injured spinal cord.

- This technology has broad application to stem cell-directed therapies that can be used to treat injury and disease.

\section{References}

1 Fitch MT, Silver J. CNS injury, glial scars, and inflammation: inhibitory extracellular matrices and regeneration failure. Exp. Neurol. 209(2), 294-301 (2008).

2 Beattie MS, Hermann GE, Rogers RC, Bresnahan JC. Cell death in models of spinal cord injury. Prog. Brain Res. 137, 37-47 (2002).
3 Liu XZ, Xu XM, Hu R et al. Neuronal and glial apoptosis after traumatic spinal cord injury. J. Neurosci. 17(14), 5395-5406 (1997).

4 Eng LF, Reier PJ, Houle JD. Astrocyte activation and fibrous gliosis: glial fibrillary acidic protein immunostaining of astrocytes following intraspinal cord grafting of fetal CNS tissue. Prog. Brain Res. 71, 439-455 (1987). 
5 Reier PJ, Houle JD. The glial scar: its bearing on axonal elongation and transplantation approaches to CNS repair. Adv. Neurol. 47, 87-138 (1988).

6 Reier PJ. The astrocytic scar as an impediment to regeneration in the central nervous system. In: Spinal Cord Reconstruction. CC Kao, RP Bunge, PJ Reier (Eds.). Raven Press, NY, USA, 163-195 (1983).

7 Fawcett JW, Asher RA. The glial scar and central nervous system repair. Brain Res. Bull. 49(6), 377-391 (1999).

8 Hu R, Zhou J, Luo C et al. Glial scar and neuroregeneration: histological, functional, and magnetic resonance imaging analysis in chronic spinal cord injury. J. Neurosurg. Spine 13(2), 169-180 (2010).

9 Colognato H, Yurchenco PD. Form and function: the laminin family of heterotrimers. Dev. Dyn. 218(2), 213-234 (2000).

10 Burgeson RE, Chiquet M, Deutzmann R et al. A new nomenclature for the laminins. Matrix Biol. 14(3), 209-211 (1994).

11 Grant DS, Tashiro K, Segui-Real B, Yamada Y, Martin GR, Kleinman HK. Two different laminin domains mediate the differentiation of human endothelial cells into capillary-like structures in vitro. Cell 58(5), 933-943 (1989).

12 Kanemoto T, Reich R, Royce L et al. Identification of an amino acid sequence from the laminin A chain that stimulates metastasis and collagenase IV production. Proc. Natl Acad. Sci. USA 87(6), 2279-2283 (1990).

13 Kibbey MC, Grant DS, Kleinman HK. Role of the SIKVAV site of laminin in promotion of angiogenesis and tumor growth: an in vivo Matrigel model. J. Natl Cancer Inst. 84(21), 1633-1638 (1992).

14 Tysseling-Mattiace VM, Sahni V, Niece KL et al. Selfassembling nanofibers inhibit glial scar formation and promote axon elongation after spinal cord injury. J. Neurosci. 28(14), 3814-3823 (2008).

15 Poon PC, Gupta D, Shoichet MS, Tator CH. Clip compression model is useful for thoracic spinal cord injuries: histologic and functional correlates. Spine 32 (25), 2853-2859 (1976).

16 Kate Roby LS. The Pill Book Guide to Medication for Your Dog and Cat. Bantam Books, NY, USA (1998).

17 Basso DM, Fisher LC, Anderson AJ, Jakeman LB, McTigue DM, Popovich PG. Basso Mouse Scale for locomotion detects differences in recovery after spinal cord injury in five common mouse strains. J. Neurotrauma 23(5), 635-659 (2006).

18 Joshi M, Fehlings MG. Development and characterization of a novel, graded model of clip compressive spinal cord injury in the mouse: part 2. Quantitative neuroanatomical assessment and analysis of the relationships between axonal tracts, residual tissue, and locomotor recovery. J. Neurotrauma 19(2), 191-203 (2002).

19 Li Y, Oskouian RJ, Day YJ, Kern JA, Linden J. Optimization of a mouse locomotor rating system to evaluate compressioninduced spinal cord injury: correlation of locomotor and morphological injury indices. J. Neurosurg. Spine 4(2), 165-173 (2006).
20 Gentleman R. Language for data analysis and graphics. Computational Graphical Statistic 5, 279-314 (1996).

21 Springer JE. Apoptotic cell death following traumatic injury to the central nervous system. J. Biochem. Mol. Biol. 35(1), 94-105 (2002).

22 Leica Microsystems. Light Microscopes. www.leica-microsystems.com/products

23 Oyinbo CA. Secondary injury mechanisms in traumatic spinal cord injury: a nugget of this multiply cascade. Acta Neurobiol. Exp. 71(2), 281-299 (2011).

24 Profyris C, Cheema SS, Zang D, Azari MF, Boyle K, Petratos $S$. Degenerative and regenerative mechanisms governing spinal cord injury. Neurobiol. Dis. 15(3), 415-436 (2004).

25 Dumont RJ, Okonkwo DO, Verma S et al. Acute spinal cord injury, part I: pathophysiologic mechanisms. Clin. Neuropharmacol. 24(5), 254-264 (2001).

26 Carlson GD, Gorden C. Current developments in spinal cord injury research. Spine J 2(2), 116-128 (2002).

27 Wu J, Stoica BA, Faden AI. Cell cycle activation and spinal cord injury. Neurotherapeutics 8(2), 221-228 (2011).

28 Beattie MS, Farooqui AA, Bresnahan JC Review of current evidence for apoptosis after spinal cord injury. J. Neurotrauma 17(10), 915-925 (2000).

$29 \mathrm{Lu} \mathrm{J}$, Ashwell KW, Waite P. Advances in secondary spinal cord injury: role of apoptosis. Spine 25(14), 1859-1866 (1976).

30 Basnak'ian AG, Baskov AV, Sokolov NN, Borshchenko IA. [Apoptosis during spinal cord trauma: prospects for pharmacological correction]. Vopr. Med. Khim. 46(5), 431-443 (2000).

31 Crowe MJ, Bresnahan JC, Shuman SL, Masters JN, Beattie MS. Apoptosis and delayed degeneration after spinal cord injury in rats and monkeys. Nat. Med. 3(1), 73-76 (1997).

32 Beattie MS. Inflammation and apoptosis: linked therapeutic targets in spinal cord injury. Trends Mol. Med. 10(12), 580-583 (2004).

33 Martin LJ. Neuronal cell death in nervous system development, disease, and injury (review). Int. J. Mol. Med. 7(5), 455-478 (2001).

34 Nielson JL, Sears-Kraxberger I, Strong MK, Wong JK, Willenberg R, Steward O. Unexpected survival of neurons of origin of the pyramidal tract after spinal cord injury. J. Neurosci. 30(34), 11516-11528 (2010).

35 Okada S, Nakamura M, Katoh $\mathrm{H}$ et al. Conditional ablation of Stat 3 or Socs 3 discloses a dual role for reactive astrocytes after spinal cord injury. Nat. Med. 12(7), 829-834 (2006).

36 Faulkner JR, Herrmann JE, Woo MJ, Tansey KE, Doan NB, Sofroniew MV. Reactive astrocytes protect tissue and preserve function after spinal cord injury. J. Neurosci. 24(9), 2143-2155 (2004).

37 Shibuya S, Yamamoto T, Itano T. Glial and axonal regeneration following spinal cord injury. Cell $A d h$. Migr. 3(1), 99-106 (2009).

38 Windle WF, Chambers WW. Regeneration in the spinal cord of the cat and dog. AMA Arch. Neurol. Psychiatry 65(2), 261-262 (1951). 
39 Busch SA, Silver J. The role of extracellular matrix in CNS regeneration. Curr. Opin. Neurobiol. 17(1), 120-127 (2007).

40 Fawcett JW. Overcoming inhibition in the damaged spinal cord. J. Neurotrauma 23(3-4), 371-383 (2006).

41 Fitch MT, Silver J. Glial cell extracellular matrix: boundaries for axon growth in development and regeneration. Cell Tissue Res. 290(2), 379-384 (1997).

42 Liu BP, Cafferty WB, Budel SO, Strittmatter SM. Extracellular regulators of axonal growth in the adult central nervous system. Philos. Trans. R Soc. Lond. B Biol. Sci. 361(1473), 1593-1610 (2006).

43 Mcgraw J, Hiebert GW, Steeves JD. Modulating astrogliosis after neurotrauma. J. Neurosci. Res. 63(2), 109-115 (2001).

44 Kawaja MD, Gage FH. Reactive astrocytes are substrates for the growth of adult CNS axons in the presence of elevated levels of nerve growth factor. Neuron 7(6), 1019-1030 (1991).

45 Gorgey AS, Dudley GA. Skeletal muscle atrophy and increased intramuscular fat after incomplete spinal cord injury. Spinal Cord 45(4), 304-309 (2007).
46 Mahoney ET, Bickel CS, Elder C et al. Changes in skeletal muscle size and glucose tolerance with electrically stimulated resistance training in subjects with chronic spinal cord injury. Arch. Phys. Med. Rehabil. 86(7), 1502-1504 (2005).

47 Dudley GA, Castro MJ, Rogers S, Apple DF Jr. A simple means of increasing muscle size after spinal cord injury: a pilot study. Eur. J. Appl. Physiol. Occup. Physiol. 80(4), 394-396 (1999).

48 Cruz CD, Cruz F. Spinal cord injury and bladder dysfunction: new ideas about an old problem. ScientificWorldJournal 11, 214-234 (2011).

49 Alluin O, Karimi-Abdolrezaee S, Delivet-Mongrain H, Leblond H, Fehlings MG, Rossignol S. Kinematic study of locomotor recovery after spinal cord clip compression injury in rats. J. Neurotrauma 28(9), 1963-1981 (2011).

50 Mata JE, Dyal LA, Slauson ME et al. Tumor imaging using technetium $-99 \mathrm{~m}$ bound to $\mathrm{pH}$-sensitive peptides. Nanomedicine 3(4), 297-305 (2007). 